\title{
TABUNG SUNTIK UNTUK HUKUM BOYLE, SIMULASI PENGUKURAN TEKANAN UDARADENGAN REAL WORLD PROBLEM SEBAGAI ALTERNATIF PEMECAHAN MASALAH
}

\author{
Maria Yuliana Kua, M.Pd. \\ Dosen Program studi Pendidikan IPA \\ STKIP Citra Bakti \\ Email:yulianakua03@gmail.com
}

\begin{abstract}
Abstrak
Telah dilakukan eksperimen untuk membuat sebuah alat sederhana berbasis hukum dasar termodinamika. Teori dasar yang digunakan berdasar hukum Boyle dan konsep gas ideal. Tujuan dari pembuatan alat ini adalah untuk menunjukkan fenomena dalam hukum Boyle ketika suhu gas yang berada dalam suatu wadah tertutup dipertahankan konstan, maka tekanan gas akan berbanding terbalik dengan volume. Alat yang dimaksud berupa sebuah wadah yang dibuat hampa udara dan diletakkan sebuah balon di dalamnya. Pada tutup wadah diletakkan beberapa selang plastik yang dihubungkan dengan tabung suntik untuk memanipulasi besar volume udaranya. Dipasang pula sebuah manometer untuk mengukur besar tekanan udaranya. Metode yang digunakan adalah dengan memberi gaya pada piston tabung suntik untuk memanipulasi besar volume yang akan memberikan pengaruh pada balon yaitu mengembang dan mengempis serta perubahan tekanan udara yang terbaca pada manometer. Media pembelajaran fisika ini didesain untuk membantu peserta didik memahami konsep termodinamika secara sederhana menggunakan real world problem sebagai alternatif pemecahan masalah.
\end{abstract}

Kata Kunci: Termodinamika, gas ideal, hukum Boyle, tabung suntik

\begin{abstract}
An experiment has been carried out to create a simple tool based on basic thermodynamic law. The basic theory used Boyle law and ideal gas concept. The purpose of creating this tool is to show the phenomenon in Boyle law, when the temperature of gas In closed vessel is constantly maintained, then the gas pressure will be inversely proportional to the volume. The tool meant here is in a form of a air-vacuum container with a balloon inside. On the lid of the container placed several plastic tubes that connected to a syringe which is used for manipulating the air volume. A manometer also is installed to measure the air pressure. Method used is applying force to the syringe piston to manipulate the volume which will affect to the balloon that will expand and deflate and in the change of air pressure read in manometer. This learning media of physics is designed to help the students to understand thermodynamic concept in a more simple way using real world problem as an alternative of problem solving.
\end{abstract}

Keyword: Thermodynamic, ideal gas, Boyle law, syringe tube 


\section{PENDAHULUAN}

1. Pembelajaran Fisika

Fisika merupakan bidang ilmu yang berada dalam rumpun sains (Ilmu Pengetahuan Alam). Hakikat pembelajaran sains (Depdiknas, 2006) adalah pembelajaran yang mampu merangsang kemampuan berpikir siswa dan meliputi lima unsur yaitu sikap, proses, produk, aplikasi, dan kreativitas. Sikap yaitu rasa ingin tahu tentang benda, fenomena alam, makhluk hidup, serta hubungan sebab akibat yang menimbulkan masalah baru dan dapat dipecahkan melalui prosedur yang benar. Proses merupakan prosedur pemecahan masalah melalui metode ilmiah. Produk berupa fakta, prinsip, teori, dan hukum. Aplikasi yaitu penerapan metode ilmiah dan konsep IPA dalam kehidupan sehari-hari. Kreativitas berhubungan dengan ide baru atau cara yang tidak biasa dalam memecahkan masalah. Omiwale (2011) menjelaskan bahwa "Physics is a science subject that deals with the fundamental constituents of the universe, the forces they exert on one another, and the effects of these forces". Mundilarto (2010) menyatakan bahwa fisika merupakan ilmu dasar yang terdiri atas fakta, konsep, prinsip, hukum, postulat, dan teori serta metodologi keilmuan. Fisika adalah ilmu yang berkaitan dengan studi tentang alam dan fenomena alam.
Adeyemo (2010) dalam penelitiannya menjelaskan bahwa fisika merupakan disiplin ilmu yang unik dan menarik. Fisika sulit untuk diajarkan dan dipahami. Fisika dapat dianggap sebagai HOT (higher order thinking). Hal ini merupakan tuntutan besar bagi siswa dalam proses pembelajaran. Lebih lanjut dijelaskan Kua (2018) bahwa kesulitan dalam proses pembelajaran disebabkan pula oleh terbatasnya sumber, sarana, dan buku fisika yang sesuai karakteristik siswa. Permasalahan dalam pembelajaran ini dapat diminimalisir dengan memilih model dan metode pembelajaran yang tepat. Kua (2016) dalam penelitiannya menjelaskan bahwa pemilihan strategi pembelajaran yang tepat akan mempengaruhi kualitas pembelajaran.Dengan demikian, dalam proses pembelajaran guru dituntut untuk dapat menciptakan pengalamanpengalaman belajar melalui pemilihan sumber belajar, model, metode, pendekatan, maupun strategi yang dapat memberikan kesempatan kepada siswa untuk berpartisipasi aktif dalam mengkonstruksi sendiri pengetahuannya dalam upaya pemecahan masalah fisika.

2. Real World Problem

McCormick (2015) dalam penelitiannya menjelaskan bahwa aktivitas pembelajaran yang didasarkan pada 
pengalaman nyata sehari-hari dapat menolong siswa untuk mentransferkan pengetahuan atau informasi tersebut ke dalam pengetahuan mereka sendiri yang dapat diaplikasikan dalam situasi yang berbeda. Killen (2009) menjelaskan bahwa terdapat tiga hal penting dari real problem yang sering dihadapi dalam kehidupan sehari-hari:

1) Ketika siswa berusaha untuk menyelesaikan real-world problem mereka perlu mengetahui alasan mengapa mereka perlu menyelesaikannya.

2) Ketika siswa dihadapkan pada real world problem, mereka seringkali tidak memiliki cukup pengetahuan atau skill untuk menyelesaikannya, karenanya harus mempelajari sesuatu yang baru.

3) Real world problem jarang memiliki hanya satu solusi dan sering tidak memiliki satu solusi terbaik.

Real world problem ditandai oleh adanya masalah nyata sebagai konteks bagi siswa untuk belajar kritis dan keterampilan memecahkan masalah serta memperoleh pengetahuan. Solusi dari real world problem memberikan perhatian khusus terhadap konteks kehidupan nyata yang saling berhubungan (Kua, 2018). Karakteristik mata pelajaran fisika ada yang sulit dan ada pula yang mudah, sehingga tidak semua materi dapat dipahami oleh siswa hanya dengan membaca, mendengar, atau memperagakan.Kua, et al (2015) menjelaskan pula bahwa "Real world problems is one of the alternative solutions which in this case is used as away to introduce the students to the real problems in understanding the concept of physics". Jika siswa dapat melihat adanya keterkaitan antara kehidupan mereka dan materi yang dipelajari, mereka akan lebih tertarik terhadap pembelajaran yang berlangsung (Kua, Aryani, Rewo, 2019).

Pada

intinya

pembelajaran dengan real world problem merupakan suatu pembelajaran yang menggunakan masalah nyata, yang dapat disajikan dalam proses pembelajaran baik dalam bentuk gambar, video, maupun media lainnya untuk merangsang dan memudahkan siswa dalam mengasosiasikan permasalahan dengan konsep fisika yang dipelajari, kemudian masalah tersebut diselidiki untuk mendapatkan solusi yang tepat.

3. Konsep Termodinamika

Dalam termodinamika dikenal 3 peubah keadaan, yakni tekanan $(P)$, volume $(\mathrm{V})$ dan temperatur $(\mathrm{T})$. Ketiga besaran tersebut bersifat saling gayut, atau biasa disebut tidak saling bebas. Perubahan keadaan gas dapat terjadi pada suhu tetap, 
tekanan tetap atau volume tetap (Indrajit, 2006).

Konsep teori yang menjadi dasar eksperimen ini adalah konsep gas ideal dan hukum Boyle. Konsep gas ideal menyatakan bahwa semua gas dengan komposisi kimia apapun pada suhu tinggi dan tekanan rendah cenderung memperlihatkan suatu hubungan sederhana tertentu di antara sifat-sifat makroskopisnya, yaitu tekanan $(\mathrm{P})$, volume $(\mathrm{V})$, dan temperatur $(T)$. Volume yang ditempati oleh gas tersebut pada suatu tekanan dan temperatur yang diberikan adalah sebanding dengan massanya (Yahdi, 1996). Konstanta tersebut akan sama dengan banyaknya mol gas ( $n$ ) dikalikan dengan konstanta gas universal $(R=8,34 \quad \mathrm{~J} / \mathrm{mol} . \mathrm{K})$. Hubungan tersebut dapat dinyatakan dalam hukum Boyle-Gay Lussac sebagai:

$$
P V=n R T
$$

Walaupun tidak ada gas yang betul-betul merupakan gas ideal tetapi gas ideal merupakan suatu konsep sederhana yang sangat berguna dalam mendekati keadaan yang sebenarnya (Widodo, 2009). Berdasarkan sifat makroskopis suatu gas, yaitu kelajuan, energi kinetik, momentum, dan massa setiap partikel penyusun gas, gas ideal memiliki sifat antara lain:

1. Suatu gas terdiri dari partikel-partikel yang disebut molekul dan setiap molekul adalah identik (sama) sehingga tidak dapat dibedakan dengan molekul lainnya.

2. Molekul-molekul gas bergerak secara acak dan memenuhi hukum gerak Newton.

3. Jumlah seluruh molekul gas sangat banyak tetapi tidak terjadi gaya interaksi antarmolekul.

4. Ukuran molekul gas sangat kecil sehingga dapat diabaikan terhadap ukuran wadah.

5. Molekul gas terdistribusi merata pada seluruh ruangan dalam wadah.

6. Setiap tumbukan yang terjadi (antara molekul dengan molekul atau antara molekul dengan dinding wadah adalah elastis sempurna).

Isotermal merupakan suatu proses perubahan keadaan gas ideal yang terjadi pada suhu tetap. Dalam hukum Boyle ditegaskan bahwa pada suatu proses temperatur konstan, tekanan gas akan berbanding terbalik dengan volumenya (Young \& Freedman, 2002). Secara matematis dinyatakan dengan:

$$
P V=\text { Konstan }
$$

Untuk gas yang berada dalam dua keadaan keseimbangn yang berbeda pada suhu konstan, maka diperoleh:

$$
P_{1} V_{1}=P_{2} V_{2}
$$

dengan: 
$P_{1}=$ tekanan gas pada keadaan

$1\left(\mathrm{~N} / \mathrm{m}^{2}\right)$

$P_{2}=$ tekanan gas pada keadaan

$2\left(\mathrm{~N} / \mathrm{m}^{2}\right)$

$V_{1}=$ volum gas pada keadaan 1

$\left(\mathrm{m}^{3}\right)$

$V_{2}=$ volum gas pada keadaan 1 $\left(\mathrm{m}^{3}\right)$

\section{METODOLOGI PENELITIAN}

Penelitian inidilakukan untuk menunjukkan proses dan hasil simulasi pengukuran tekanan udara menggunakan tabung suntik untuk Hukum Boyle dengan real world problem sebagai alternatif pemecahan masalah.

1. Identifikasi Variabel
1) Variabel Manipulasi : Tekanan udara
2) Variabel Kontrol : Suhu
3) Variabel Terikat : Volume udara

2. Definisi Operasional Variabel merupakan wadah yang kedap udara.
1) Wadah yang digunakan
2) Tabung suntik yang digunakan berjumlah 5 buah
3) Digunakan sebuah balon untuk menunjukkan fenomena pengaruh tekanan udara terhadap perubahan volume balon.

3. Alat dan Bahan
1) Balon tiup
2) Selang plastik $1,5 \mathrm{~m}$
3) Sambungan selang
4) Lem paralon
5) Tabung suntik

6) Wadah palstik kecil

7) Manometer

Cara mendapatkan alat dan bahan:

1) Bahan-bahan poin 1) sampai 4) dapat diperoleh di toko alat tulis dan bangunan dengan rincian biaya:

Balon tiup 6 Rp 2.000,00 buah

Selang palstik Rp 3.000,00 Sambungan Rp 500,00 selang

Lem paralon Rp $9.000,00$

2) Bahan-bahan poin 5) dan 6) dapat menggunakan bahan yang terdapat di rumah.

3) Manometerdapat diperoleh dengan cara meminjamnya, misalnya di laboratorium fisika.

4. Rancangan Percobaan

1) Prinsip pembuatan media ini didasarkan pada konsep termodinamika.

2) Eksperimen dengan tabung suntik ini didesain untuk menunjukkan fenomena dalam hukum Boyle yaitu tekanan gas berbanding terbalik dengan volumnya melalui mengembang dan mengempisnya balon tiup yang terdapat dalam wadah hampa udara.

5. Prosedur Kerja

1) Menyiapkan alat dan bahan yang dibutuhkan dalam percobaan ini sebagaimana yang telah diuraikan di atas.

2) Meniup balon dengan ukuran yang dapat disesuaikan dengan ukuran wadah. Menggunakan wadah plastik yang bening agar dapat 
memperlihatkan fenomena ketika balon mengembang dan mengempis.

3) Menutup wadah secara rapat dengan tujuan membuatnya menjadi kedap udara. Untuk melakukan ini dapat menggunakan lem paralon yang direkatkan pada sekeliling penutup wadah plastik. Selanjutnya, sebelum menutup wadah tersebut, dapat menambahi balon tiup yang digunting seukuran lingkaran penutup wadah, agar dapat memaksimalkan kerapatan penutupnya.

4) Kemudian, memberi lubang pada penutup wadah seukuran sambungan selang sebanyak jumlah tabung suntik yang digunakan.

5) Selanjutnya, memasang selang pada sambungan selang lalu menghubungkan dengan tabung suntik. Pada sekeliling sambungan selang dapat menambahkan pula dengan lem paralon agar dapat benar-benar mencegah keluar masuknya udara.

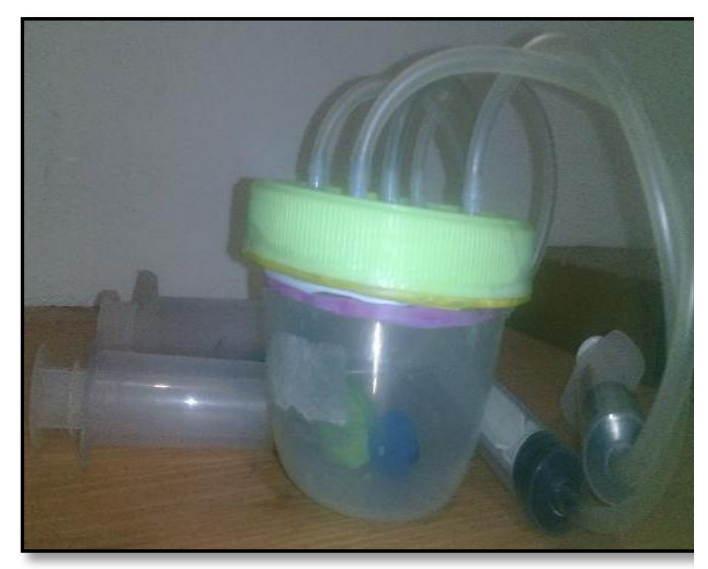

Gambar 1.Tabung Suntik untuk Hukum

Boyle

6) Setelah alat dirangkai, memastikan terlebih dahulu apakah wadah tersebut benarbenar telah kedap udara.

7) Prinsip kerja alat tersebut adalah dengan menarik dan mendorong piston tabung suntik, kemudian dapat memperhatikan apa yang terjadi pada balon tiup dalam wadah.

8) Selanjutnya, pada salah satu sambungan selang dipasang manometer untuk membaca besar tekanan udara dalam wadah tersebut.

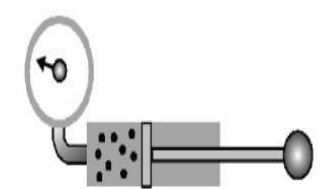

(a)

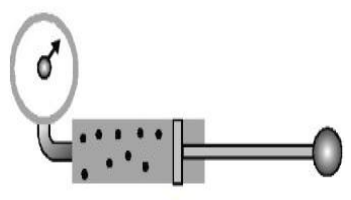

(b)
Gambar 2. Tabung suntik yang dipasang Manometer 


\section{HASIL DAN PEMBAHASAN}

1. Hasil

Berdasarkan ekseperimen yang dilakukan, dihasilkan tabung suntik yang dikembangkan dengan prinsip dasar Termodinamika untuk menunjukkan Hukum Boyle. Hasil eksperimen ditunjukkan pada Tabel di bawah ini.

Tabel 1. Hasil Eksperimen menggunakan Tabung Suntik

\begin{tabular}{|c|c|c|c|c|}
\hline$t\left({ }^{0} \mathrm{C}\right)$ & $P_{a}(\mathrm{~atm})$ & $P_{m}(\mathrm{~atm})$ & $V\left(\mathrm{~cm}^{3}\right)$ & $\left(P_{m}-P_{\mathrm{a}}\right) V$ \\
\hline \multirow{5}{*}{25} & 0,3 & 270 & 104 \\
\cline { 3 - 5 } & & 0,5 & 122 & 105 \\
\cline { 3 - 5 } & \multirow{3}{*}{0,02} & 0,7 & 104 & 105 \\
\cline { 3 - 5 } & & 1,0 & 76 & 104 \\
\cline { 3 - 5 } & 1,7 & 62 & 104 \\
\cline { 3 - 5 } & 2,1 & 50 & 104 \\
\cline { 3 - 5 } & 3,1 & 34 & 105 \\
\cline { 3 - 5 } & & 4,8 & 22 & 105 \\
\cline { 3 - 5 } & & 8,7 & 12 & 104 \\
\hline
\end{tabular}

Hubungan tekanan dan volume berdasarkan eksperimen di atas, disajikan pada grafik di bawah ini.

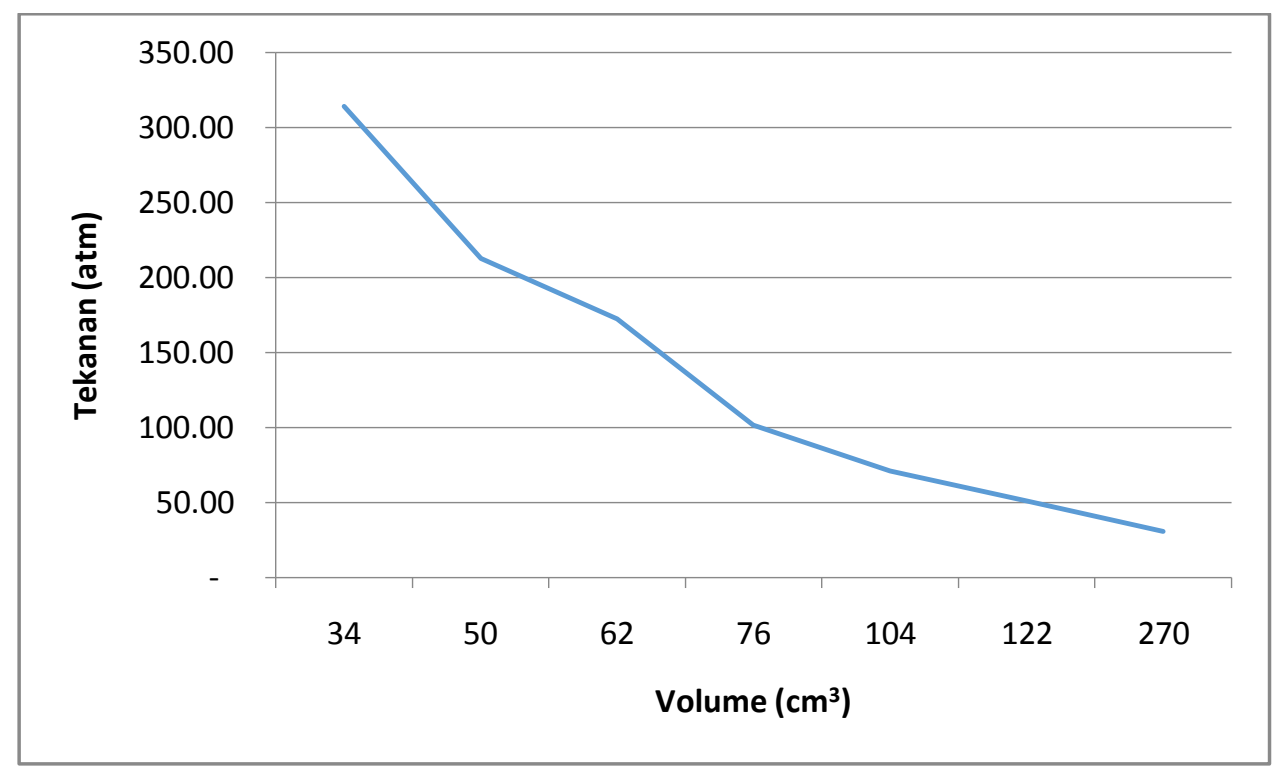

Gambar 3. Grafik Hubungan Tekanan dan Volume 


\section{Pembahasan}

Gambar di bawah ini menunjukkan prinsip kerja dari alat yang dibuat dalam percobaan ini. Tinjau gas yang terdapat dalam bejana tertutup kedap udara, pada suhu konstan.

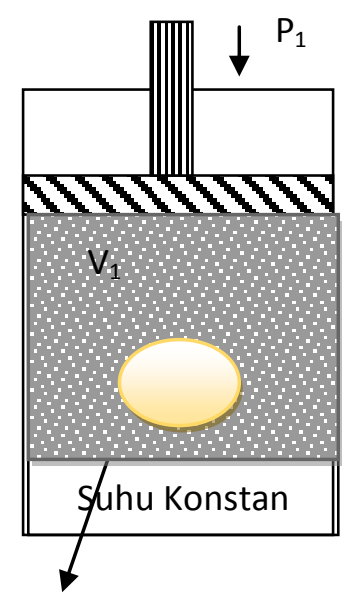

Balon Mengembang

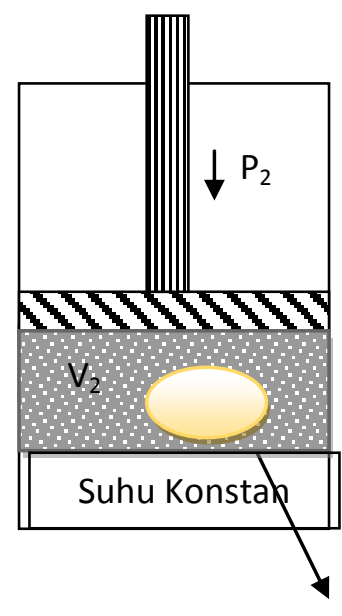

Balon Mengempis berlangsung

dapat

dipertahankan konstan.

Fenomena

yang

ditunjukkan dalam percobaan ini sesuai dengan bunyi hukum Boyle yaitu apabila gas yang berada dalam bejana tertutup dipertahankan konstan, maka tekanan gas berbanding terbalik dengan volumenya.

Selanjutnya, dapat dilakukan pengukuran tekanan udara menggunakan manometer yang dipasang pada salah satu sambungan selang. Dengan demikian, dapat dihitung besar volume gas untuk tiap-tiap kenaikan tekanan.

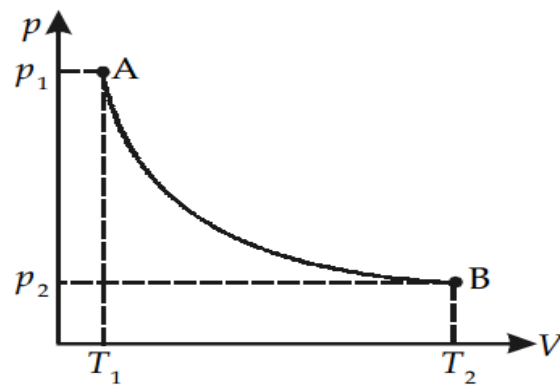

Gambar 5.Grafik hubungan tekanan dan volume gas pada suhu konstan
Pada saat menarik piston tabung suntik ke atas, maka tekanan gas akan turun dan volume gas akan naik yang ditunjukkan melalui mengembangnya balon tiup dalam wadah kedap udara. Sementara itu, ketika piston tabung suntik digerakkan ke bawah maka tekanan gas akan naik dan volume gas akan turun yang ditunjukkan melalui mengempisnya balon tiup dalam wadah kedap udara. Jika piston digerakkan secara perlahanlahan, maka gas akan tetap dalam keseimbangan termal sehingga suhu gas selama

\section{KESIMPULAN}

Berdasarkan percobaan yang dilakukan ini dapat ditunjukkan fenomena pada hukum Boyle mengenai hubungan tekanan, volume, dan suhu. Penjelasan fenomena ini dapat dilakukan secara sederhana dengan prinsip pemanfaatan alat dan bahan yang terdapat di sekitar kehidupan peserta didik. Media dengan bahan tabung suntik ini didesain berdasarkan konsep dasar 


\begin{abstract}
termodinamika yang dapat membuktikan hukum Boyle yaitu apabila gas yang berada dalam bejana tertutup dipertahankan konstan, maka tekanan gas berbanding terbalik dengan volumenya.
\end{abstract}




\section{DAFTAR PUSTAKA}

Adeyemo, S. A. (2010). Background and Classroom Corelates of Students' Achievement in Physics, International Journal of Educational Research and Technology, 1, 25-34.

Depdiknas. (2006). Peraturan Pemerintah RI Nomor 22, Tahun 2006, tentang Standar Isi.

Halliday, Recnick, \& Walker. (2010). Fisika Dasar Edisi 7 Jilid 2 (Terjemahan Tim Pengajar Fisika ITB). Jakarta: Erlangga.

Hussain, A., Azeem, M., \& Shakoor, A. (2011). Physics Teaching Methods: Scientific Inquiry Vs Traditional Lecture. International Journal of Humanities and Social Science, Vol. 1, No. 19, 269-276.

Indrajit, D. (2009). Mudah dan Aktif Belajar Fisika. Jakarta: Pusat Perbukuan Departemen Pendidikan Nasional.

Kua, M.Y, et al. (2015). Analysis of the Speed of a Moving Object through the Application of Videopad to Teach Mechanical Concepts Based on a Real World Problem. Harmonization of Science, Technology, and society (STS) in science Learning to Prepare $21^{\text {st }}$ Century Generation: Yogyakarta.

Kua, M. Y. (2016). Pengaruh Penerapan Model Pembelajaran Real World Problem Solving terhadap Kemampuan Kognitif dalam Meretensi dan Mentransfer serta Kemampuan Berpikir Kritis Siswa Kelas X SMA Negeri 1 Bajawa. Universitas Negeri Yogyakarta.

Kua, M.Y. (2018). Kepraktisan Penerapan Model Pembelajaran Real World Problem Solving dalam Pembelajaran Fisika Di sekolah Menengah Atas. Jurnal IImiah Pendidikan Citra Bakti, 5 (1), 24-34.

Kua, M.Y. (2018). Pembelajaran Real world Problem Solving dengan Setting Argumentasi untuk Meningkatkan Kemampuan Berpikir Kritis Siswa dalam Pembelajaran Fisika. Jurnal IImiah Pendidikan Citra Bakti, 5 (2), 93-102.

Kua, M.Y., Aryani, N. W. P., Rewo, J. M. (2019). Penerapan Model Pembelajaran Kooperatif Tipe Team Assisted Individualization dengan Real world Problem. Journal of Education Technology, 2 (4), 169-176.

McCormick, N. J. (2015). Engaging Students in Critical Thinking and Problem

Solving: A Brief Review of the Literature. Journal of Studies in Education, 5, 100-113.

Yahdi, Umar. (1996). Pengantar Fisika Mekanika. Jakarta: Gunadarma.

Widodo, T. (2009). Fisika untuk SMA dan MA kelas X. Jakarta: Pusat Perbukuan Departemen Pendidikan Nasional. 
Young, H. D., \& Freedman, R.A. (2002). Fisika Universitas Jilid I Edisi kesepuluh. Jakarta: Penerbit Erlangga. 